\title{
How Non-Epistemic Values Can Be Epistemically Beneficial in Scientific Classification
}

\author{
Soohyun Ahn \\ Department of Philosophy \\ University of Calgary
}

\begin{abstract}
The boundaries of social categories are frequently altered to serve normative projects, such as social reform. Griffiths and Khalidi argue that the value-driven modification of categories diminishes the epistemic value of social categories. I argue that concerns over value-modified categories are an endorsement of problematic assumptions of the value-free ideal of science. Contrary to those concerns, non-epistemic value considerations can increase the epistemic success of a scientific category. For example, the early history of the category infantile autism shows how non-epistemic value considerations can contribute to delimiting and establishing infantile autism as a distinct category in mainstream psychiatry. In the case of infantile autism, non-epistemic considerations have led to a new interpretation of existing data, the expansion of research to include biology, and the creation of diagnostic criteria that further contribute to collecting relevant data. Given this case study, we see that non-epistemic considerations may not be epistemically detrimental but can be epistemically beneficial in scientific classification.
\end{abstract}




\title{
How Non-Epistemic Values Can Be Epistemically Beneficial in Scientific Classification
}

\author{
Soohyun Ahn \\ Department of Philosophy \\ University of Calgary
}

\section{Introduction}

Paul Griffiths (1997, 2003, 2004) defines natural kinds as categories that allow reliable extrapolation from known to unknown instances. Such kinds have greater epistemic value as they are further confirmed by empirical evidence. He notes that the boundaries of social categories are frequently altered to serve normative projects, such as social reform, without "theoretical warrant" (Griffiths, 1997, p. 196). This observation becomes a source of trouble for him since it is possible for a category to be pressured to respond to two different types of projects-epistemic and normative - simultaneously. According to Griffiths, a category under such pressure ends up being fractured and loses its epistemic utility (2004, p. 909).

Muhammad Ali Khalidi (2013) develops Griffiths' observation into a substantial worry for social, psychological, and psychiatric categories being natural kinds. These categories are employed to describe and explain human behavior and are value-laden to some extent. The problem Khalidi focuses on is that "there is often an added moral dimension to them that puts pressure on us to modify the category in certain ways" (ibid., p. 195). For Khalidi, the aim of scientific classification is to have categories that reflect "real causal patterns" in the world. The more accurately they reflect causal patterns, the more epistemically useful scientific categories are. He argues that when non-epistemic values, such as social, moral, and political values, influence delimiting scientific categories, these categories may no longer track the causal structure of the world. Khalidi's prescription is that scientists should be guided solely by epistemic purposes and eliminate non-epistemic purposes altogether.

Griffiths and Khalidi present non-epistemic value considerations as harmful in scientific classification. Non-epistemic value influences on scientific categories result in the epistemically detrimental consequences of hindering scientific understanding (for Griffiths) and distracting us from the causal structures of the world (for Khalidi). It is noteworthy that such a view regarding non-epistemic values is part and parcel of the value-free ideal (VFI) in science. The current version of the VFI endorses an exclusive commitment to epistemic values while allowing no role for non- 
epistemic values in the core of scientific reasoning, e.g., generating data and assessing theories. ${ }^{1}$ The ideal maintains that scientific objectivity and integrity are achieved to the extent that scientific reasoning is insulated from non-epistemic value influences. If we see the concern over values affecting categories through the lens of the VFI, the normative implication for scientific classification becomes clear: scientists should strive to minimize the influence of non-epistemic values in identifying natural kinds. This implication is clearly echoed in Khalidi's suggestion of excluding non-epistemic purposes in the pursuit of natural kinds. However, as will be shown in this paper, far from being epistemically detrimental, value-driven research in scientific classification can be epistemically beneficial.

This paper is organized as follows. In section 2, I address the concern over value-modified categories by analyzing the case study of child abuse presented by several philosophers (Hacking, 1988, 1991, 1999; Griffiths, 1997, 2004; Khalidi, 2013). Upon reflection, the category child abuse is not a good example to motivate this concern. In section 3, I provide another case study, infantile autism, to illustrate how non-epistemic value considerations can contribute to the epistemic improvement of that category. In section 4, I respond to some potential objections to my account with the help of some arguments against the VFI. I conclude that the argument for rejecting nonepistemic values in identifying natural kinds in the social and psychological sciences is not effective.

\section{The Concern: Illegitimacy of Non-Epistemic Values in Natural Kinds}

In this section, I pursue two aims. First, I want to elaborate Griffiths' and Khalidi's concerns over the value-driven modification of categories. They focus on the case study of the category child abuse presented by Ian Hacking $(1988 ; 1991 ; 1999)$. Second, I want to point out that the category of child abuse is not a good example for raising their concerns. This is because the category of child abuse does not show the conflict between epistemic and non-epistemic purposes.

In his 2004 article, Griffiths introduces the notion of "normative kinds," which are contrasted with natural kinds. A category is a "normative kind" when it "derives its unity from a role in normative practices... rather than from any role it may have in describing and explaining behavior" (p. 903). Griffiths considers the category of child abuse as a prime example of a normative kind. We place seemingly unrelated behaviors, such as neglect and sexual harassment, in the category child abuse. This practice is justified by our moral approval or disapproval of certain types of human behavior. Consider, for example, corporal punishment. Until recently, physical punishment for children was common and even encouraged as an effective means to teach children to conform to authority and social order. Identifying corporal punishment as a type of child abuse can be

\footnotetext{
${ }^{1}$ Here I follow Daniel Hicks' formulation of the VFI, according to which, "ethical and political values may not legitimately influence the standards for acceptance and rejection in" the "epistemic phase" of scientific inquiry (Hicks, 2014, p. 3274). Many formulations articulate the VFI in terms of "absence of contextual values" and "exclusive commitment to epistemic values in scientific reasoning" (Reiss \& Sprenger, 2017, p. 21).
} 
explained by the change in our normative attitudes toward children and our preference for autonomy and self-fulfillment over social conformity and social stability.

In line with Hacking, Griffiths argues that socially or politically value-laden concepts, such as the concept of child abuse, "are used to structure social systems, to further the interests of individuals or groups, and to promote programs of political action" (1997, p. 7). According to Griffiths, studying this type of category modification reveals "the full range of dynamics at work in conceptual change" and, in doing so, directs our attention to social issues and pushes us to take action to address them (ibid., p. 198). For example, if common wisdom views leaving children at home without adult supervision as a form of child abuse, then society should seek solutions for those parents who cannot afford childcare. However, Griffiths is clear that such a value-driven alteration of a category does not improve our scientific understanding of the relevant phenomena (ibid., 200). Non-epistemic projects are seen as forces that sidetrack the discovery of natural kinds.

Khalidi (2013) builds on Hacking's (1991) analysis of legal attempts in the USA to classify fetal abuse as a form of child abuse. By doing so, he wants to reinforce Griffiths' idea that the moral dimensions of a category can undermine the epistemic roles the category plays: normative kinds or "evaluative kinds" can reduce their "epistemic efficacy" when "they are being put (at least partly) to evaluative uses (Khalidi, 2013, pp. 162-163). Let me add some more details about legal attempts to charge pregnant women with child endangerment when abusing substances. The Wisconsin State Legislature passed the so-called "Cocaine Mom" Law in 1997. Under this law, pregnant women who drink alcohol or take drugs are indicted on charges of abusing their "unborn child" ("1997 Wisconsin Act 292"). The issue of whether a fetus should be understood as an "unborn child" possessing legal rights is highly controversial. As Khalidi speculates, the legislature's move was mainly motivated by the desire for moral censure, especially by pro-life advocates. Khalidi regards the fetal abuse case as a clear example demonstrating how "a valuedriven revision of a category pulls in a different direction from the epistemic," and the valuedriven modification undermines the epistemic, thereby rendering the category not a natural kind (Khalidi, 2013, p. 163). According to Khalidi, if fetal abuse cases do not share the same cause and effect with other incidents of child abuse, they will add exceptions to the phenomenon of child abuse. Having a heterogeneous category prevents scientists from generalizing and explaining the phenomenon of child abuse. Different purposes "serve different needs and can therefore come to be opposed to one another (ibid., p. 162). He goes on to argue that "there is a legitimate reason for thinking that some social categories do not track natural kinds when they are being put (at least partly) to evaluative uses" (ibid., p. 162). Thus, Khalidi concludes that value-driven modifications of a category are likely to frustrate the epistemic aims of generalization and explanation, thereby becoming "the largest obstacle to the discovery of natural kinds in the social sciences" (ibid., p. 163).

It is questionable whether evaluative or non-epistemic dimensions of a scientific category pose a threat to the good epistemic functioning of that category. One line of research that can test Khalidi's claim is etiological research on intergenerational transmission of child abuse. It has been widely studied whether and to what extent the parental history of abuse plays a causal role in the perpetration of abuse. Research on the transmission hypothesis has an epistemic aim of revealing the causal relation of the transmission of abuse from one generation to the next. At the same time, 
it aims to find effective intervention measures to break the cycle of abuse. It would be helpful to review a recent study on the intergenerational transmission hypothesis to see whether nonepistemic aims sidetrack epistemic aims. The research conducted by RaeAnn E. Anderson and her colleagues (2018) is motivated to identify a reliable predictor of child abuse potential among racially diverse mothers who reside in domestic violence shelters. That research is also dedicated to providing practical help for the mothers in shelters since they belong to "a marginalized group with unique vulnerabilities" (ibid., p. 88).

Anderson's team's research was successful in achieving the two aims without sacrificing one for the other. In terms of epistemic aims, it discovered that the diagnosis of posttraumatic stress disorder (PTSD) caused by domestic violence is strongly associated with the perpetration of child maltreatment, and it disproved the common assumption that the history of child abuse is the most powerful predictor of future abuse. In terms of non-epistemic aims, the research advocated serving the mental health needs of mothers by customized intervention strategies (e.g., home-delivered care by experts other than doctors, the offering of services outside of traditional office hours and so on.) (ibid., p. 88). In this research, serving the non-epistemic aim of helping mothers in domestic violence shelters does not stand in the way of revealing the causal path of child abuse. In other words, epistemic and non-epistemic aims need not be opposed to one another.

Griffiths' and Khalidi's concerns derive from observing the co-existence of epistemic and nonepistemic aims within social categories. In this section, I have examined the category of child abuse to see to what extent it can motivate their concern. Based on the purported clash between epistemic and non-epistemic purposes, Griffiths and Khalidi frame the latter purposes as a hindrance to attaining the former. However, the category of child abuse is not a good case for raising their concerns. As Hacking and Griffiths point out, the category of child abuse is heavily normative from inception. Further, as seen in the previously cited research, the way child abuse figures in epistemic practice is tightly entangled with non-epistemic considerations. However, more importantly, non-epistemic considerations need not hinder epistemic aims. Indeed, in the next section, we will see that normative, non-epistemic considerations can help promote epistemic ends.

\section{Infantile Autism}

In this section, I examine the early history of the category of infantile autism. In common with other psychiatric categories, the concept of infantile autism is loaded with normative assumptions about what counts as normal behaviors, such as our positive evaluation of communicative ability and social interaction. When it first appeared in the literature in the $1940 \mathrm{~s}$, it was understood as a psychosis mainly caused by emotional disturbance, leaving cognition intact (Zeldovich, 2018). However, the psychogenic explanation gradually gave way to neurobiological explanations through the mid-twentieth century. With progress in genetics and neurobiology, infantile autism ${ }^{2}$

\footnotetext{
${ }^{2}$ In the early 1990 s, the idea that autism is not a single condition, but a spectrum of disorders different in degree and types was proposed. In the fifth edition of the Diagnostic and Statistical Manual of Mental Disorders (DSM-5), Asperger's disorder, childhood disintegrative disorder, and pervasive developmental
} 
has been identified as a neurodevelopmental disorder, and the role of combined genetic and environmental risk factors has been extensively studied (Chaste \& Leboyer, 2012; Lai et al., 2014). In 1980, infantile autism was finally recognized by mainstream psychiatry as a formal developmental disorder in the DSM-III. My case study tracks what drove the change in viewing infantile autism as a psychosis to a distinct neurodevelopmental disorder. By focusing on the role of value commitments, I aim to show the following: i) how research motivated by non-epistemic value judgments led to a critical examination of the received view, thereby revealing its empirical inadequacy; ii) how value-driven research led to the expansion of the research field; and iii) how value commitments contributed to the creation and development of diagnostic criteria, helping to demarcate the category.

\subsection{Mothers Blamed for Infantile Autism}

Until the mid-twentieth century, autistic children were not distinguished from children who were schizophrenic or mentally ill. It was the child psychiatrist Leo Kanner (1943) who first identified infantile autism as a distinct group. He provided detailed studies of eleven children who exhibited traits that were different from the traditional description of such children as "feebleminded or schizophrenic" (ibid., p. 242). The characteristics of the children Kanner noticed included extreme autistic aloneness, an inability to relate in an ordinary way to people and situations, and an anxiously obsessive desire for the maintenance of sameness. Kanner was particularly attentive to the parental personalities: most of the parents were highly intelligent but rarely appeared warmhearted (ibid., p. 250). In a subsequent paper, he analyzed parental characteristics and concluded that "parental coldness, obsessiveness, and a mechanical type of attention to material needs only" is the main cause of infantile autism (Kanner, 1949, p. 425). The image of cold and unloving parents of autistic children has continued since then and has deeply influenced subsequent research. The mother-blaming account, succinctly captured in the term "refrigerator mother," was popularized by the child development specialist Bruno Bettelheim (1967). Not surprisingly, when professionals diagnosed a child with autism, the whole family, especially the mother, suffered from the classification. ${ }^{3}$

\subsection{Empirical Inadequacy of the Received View}

It was Bernard Rimland's book Infantile Autism: The Syndrome and Its Implications for a Neural Theory of Behavior (1964) that initiated modern autism research by replacing the mainstream psychogenic views about autism (Associated Press, 2006; Maugh II, 2006; Casanova \& Casanova, 2019). The book was a product of Rimland's five years' research on autism after his first-born son was diagnosed with it. Though Rimland was a research psychologist, he was ignorant of autism and perplexed by his son's unusual behaviors. When he learned about autism and its purported cause, he was hurt by the "pernicious implications" of the psychogenic hypothesis (Rimland, 1964, p. 65). He deplored the added "heavy burden of shame and guilt" placed on the parents of autistic

disorder-not otherwise specified (PDD-NOS) were brought together with autistic disorder to form a single category of "autism spectrum disorder."

${ }^{3}$ Hacking also notes in his study of autism, the purported cause - cold mothering — "damaged" the whole family (Hacking, 1999, p. 115). Unfortunately, he does not tell us what propelled the replacement of the mother-blaming view with the currently endorsed view. 
children and criticized the "heartless and inconsiderate" nature of the psychogenic view (ibid., p. 65). In the book, he declared that "there is no need for the parents of these children to suffer the shame, guilt, inconvenience, financial expense and marital discord which so often accompany the assumption of psychogenic etiology" (ibid., p. 40).

Since the dominant view was based on the psychogenic account, it was common for practitioners to inspect parental characteristics. For example, practitioners tended to report in their papers the details of conversations with the mother to show how she exemplified the "typical mother" with "cold, impersonal, and ritualistic" attitudes towards her child (For example, see Eveloff, 1960, pp. 77-78). The standard of explanation in pediatric psychiatry was prejudiced against parents, especially mothers. To argue against this trend, Rimland carefully reviewed cases in the literature to propose alternative explanations. He realized that much of the evidence supporting the psychogenic view was compatible with or better fit the biological hypotheses. One common observation made by psychogenic theorists was that "[a]utistic children are behaviorally unusual from the moment of birth" (Rimland, 1964, p. 51). For Rimland, it was a strong indicator of neurobiological causation of autism. Thus, it came as a surprise to him that little attention was paid to the innateness of autism, and even Kanner, who first recognized autism as an innate condition, did not investigate deeper the biological roots of autism. ${ }^{4}$ One distinguishing feature of autism from schizophrenia was extreme aloneness (Kanner, 1943, p. 242). Kanner highlighted this autistic aloneness in terms of the relationship with the mother and interpreted the withdrawal of a child from the mother as an act of seeking comfort in solitude (Kanner, 1949, p. 425). Rimland challenged this explanation by citing animal experiments where if offspring are raised by indifferent mothers, then the offspring exhibit continued efforts to draw the mother's attention, rather than turning away from the mother (Rimland, 1964, pp. 44-45). Thus, Rimland expanded what counted as a legitimate explanation in mainstream psychiatry by exposing the weaknesses of the psychogenic view and, at the same time, by showing the superiority of biological explanations in many of the cases.

\subsection{The Expansion of the Research Area}

Rimland focused on suggesting alternative explanations to the psychogenic explanation. He wanted to expand the research field to include neurobiology that rarely figured in the literature. For Rimland, the most serious problem of the psychogenic account was that it discouraged researchers from searching for the biological basis of autism. If autism could be thoroughly explained by psychogenic factors, then any attempt to find neurobiological causes would be futile:

So long as the practitioners who actually deal with autistic children feel satisfied that the disease is largely or entirely psychogenic, biologically trained research

\footnotetext{
${ }^{4}$ Kanner briefly suggested the biological roots of autism at the end of his seminal paper: "these children have come into the world with innate inability to form the usual, biologically provided affective contact with people" (Kanner, 1943, p. 250). He also occasionally acknowledged the biological underpinnings of autism (e.g., Eisenberg and Kanner 1956). Despite his initial insight, however, Kanner persistently emphasized parental coldness as a primary cause of autism in his ensuing research and magazine interviews (e.g., Kanner 1960).
} 
workers will feel disinclined to concentrate their efforts on the problem. (ibid., p.

40)

Having the belief that "no avenue for learning all that we can about the etiology of mental disorder should be unexplored," Rimland proposed multiple lines of research that seemed to be fruitful (ibid., p. 61).

One thing Rimland noticed was the relationship between mental disorder and complications of pregnancy. Atypical behaviors of autistic children might be "the consequences of prenatal stress rather than of affectional insufficiency" (ibid. p. 145). In his support of this line of research, Rimland emphasized how biological hypotheses can shift "the burden of guilt from purely speculative parental influences to proven prenatal factors" (ibid., p. 145; emphasis in original). Rimland also noted other features that called for biological explanations; for example, the higher frequency of diagnosis of autism in boys than girls.

Another fruitful line of research for Rimland was "the brain mechanisms for processing information" (ibid., p. 144). To put his idea in action, he established the Institute for Child Behavior Research (now known as the Autism Research Institute, ARI) in 1967. The institute began to fund biologically driven "research in immune, gastrointestinal, metabolic, neurological, and sensory issues" and research aiming to find treatments for autism. It is clear that Rimland's analysis of the received view expanded the field of study to cover the neurobiological research that was urgently needed at that time (Crowell et al., 2019). Rimland is regarded as a pathfinder who "reoriented research from a focus on the parents to a focus on the brain" (Carey, 2006, p. A21).

At this point, we need to be reminded of what propelled Rimland to advocate the expansion of the research filed to include neurobiological research. As a parent of an autistic son, he was fighting against the prejudiced view about parents with autistic children. Not only was the psychogenic view inadequate in its evidential standing, but it also had pernicious implications for the emotional well-being of the parents. In his objections to the psychogenic account, he asserted that "there is no need for the parents of these children to suffer the shame, guilt, inconvenience, financial expense and marital discord which so often accompany the assumption of psychogenic etiology" (Rimland, 1964, p. 40). His non-epistemic value judgments, such as that the well-being of parents with autistic children is important, caused him to expand the research area.

\subsection{Creation of Diagnostic Checklist for Parents}

Another achievement of Rimland is the creation of a diagnostic checklist for parents. As a parent of an autistic child, he was aware of the difficulties faced by families with children suspected of being autistic. Part of the difficulty was the lack of expertise - only a handful of professionals were competent in diagnosing infantile autism in the 1960s (Shattock, 2006). Another difficulty parents faced in the 1950s and 1960s was antagonistic attitudes and pointed questions, such as "Why do you hate your child?" from their visits to professionals and their casual interactions with acquaintances (Grove, 1984; Baker, 2010; Silberman, 2015).

To assist the perplexed and distressed parents, Rimland developed a rough checklist, the "Diagnostic Checklist for Behavior-Disturbed Children (Form E-1)," building on existing criteria 
available to professionals. It was a systematic diagnostic assessment tool, but the primary target was the parents. Designed to be completed by parents, E-1 questionnaires comprised of "a carefully selected range of symptoms rather than more abstract and inconsistently defined concepts, especially of emotional withdrawal" (Lord \& Corsello, 2005, p. 744). ${ }^{5}$

What is important in our discussion is that Rimland's motivation for developing a checklist for infantile autism was not entirely epistemic. Rimland's diagnostic form is well-known to be "most useful to parents who are beginning to familiarize themselves with behaviors associated with autism, rather than as a measure of standard diagnoses of autism or related disorders" (Lord \& Corsello, 2005, p. 744). Of course, the checklist had several epistemic aims including collecting statistical data (Rimland, 1964, 1993) or distinguishing infantile autism from other childhood disorder and types of mental retardation (Rimland, 1964, 1971; Douglas \& Sanders, 1968; Boullin, Coleman, O’Brien, \& Rimland, 1971; Lord \& Corsello, 2005). However, as Rimland remarked here and there, the primary aim of the checklist was to assist the perplexed parents. As mentioned earlier, families with autistic children greatly suffered from prejudice on top of financial burdens. To share their emotional struggles, Rimland always answered phone calls from parents, whether day or night, listening to them with all his heart. To reduce their financial burdens, Rimland made the checklist available to parents free of charge, including scoring, analysis, and delivery of results back to the parents ${ }^{6}$ (Rimland, 1984; Lord \& Corsello, 2005).

Rimland's value judgments (e.g., the parents with autistic children should not suffer from the prejudiced view against them) drew the cooperation of the parents. When the checklist was published as an appendix to Rimland's book, many parents with autistic children completed the list and mailed it back to Rimland for his records. It is said that some parents reported symptoms of their autistic children that were not recognized by practitioners at that time (Edelson, 2014). With the help of sympathetic parents, the list quickly improved to become the "Diagnostic Check List (Experimental Form 2)" within a year of the first printing of the book. The updated questionnaire included "questions gleaned from the reading of numerous letters and reports from parents" (Rimland, 1971, p. 163). The ARI created a large database based on the form and analyzed results from more than 40,000 cases. As a result, it can now differentiate more than ten types of infantile autism.

Given the common belief that scientific research ought to be free from personal, social, political, and cultural values, it is noteworthy that in this case, the incorporation of a researcher's values produced epistemically fruitful outcomes. Those values helped delimit the boundaries of the category by expanding its extension to neurobiological explanations. ${ }^{7}$ As mentioned earlier, it was

\footnotetext{
${ }^{5}$ Given the prevalent tendency of professionals at that time to disregarded the reliability of retrospective parental reports, the checklist represented a significant move that took seriously the engagement of parents in the diagnosis of autism (Rimland, 1971).

${ }^{6}$ Looking back at the last thirty years since the publication of his book, Rimland judged the increased role of parents in autism research as a crucial contribution of his book. He writes: "parents are taking a much stronger and more active role in determining what is done to help their children... These changes are taking place on both the educational and biological fronts" (Rimland, 1994, p. 3).

${ }^{7}$ The "defect-based" idea that autism is a disease (disorder) to be treated is now outdated, especially in considering the current neurodiversity movement (Jaarsma \& Welin, 2012). According to the
} 
in 1980 when the DSM-III was published that infantile autism was accorded the status of a separate category. However, exactly how did Rimland's creation of the diagnostic checklist contribute to the demarcation of the category of infantile autism?

In his pioneering paper, Kanner (1943) recognizes the distinctive characteristics of the eleven children and named the shared condition infantile autism. However, he did not aggressively pursue the idea that infantile autism is separable from childhood schizophrenia. For example, in his second paper on infantile autism, Kanner regarded infantile autism "as the earliest possible manifestation of childhood schizophrenia" (Kanner, 1949, p. 419). He didn't believe that "there is any likelihood that early infantile autism will at any future time have to be separated from the schizophrenias" (ibid., pp. 419-420). Therefore, coining the term infantile autism can be credited to Kanner, but it is controversial whether he deserves the credit for demarcating infantile autism from mental retardation or childhood schizophrenia. When Rimland created the checklist, it included questions related to childhood schizophrenia, mental retardation, emotional disturbance, et cetera. The inclusion of the traits that are non-autistic was meant to differentiate genuine cases of autism from other types of psychoses. The scoring of the checklist was based on "the difference between his autism (+) and nonautism (-) scores." (Rimland, 1971, p. 164). Moreover, when infantile autism was listed in the DSM-III, its definition adopted a working definition proposed by Rimland and other parents of autistic children (Badesch, 2011, p. 9). ${ }^{9}$ So, Rimland provided a clearer division between infantile autism and childhood schizophrenia as well as how to distinguish the two.

\subsection{Other Case Studies: Divorce and Intimate Partner Violence}

At this point, let me compare my case study with two other noteworthy ones, divorce and intimate partner violence, presented by Elizabeth Anderson (2004) and Janet Kourany (2010), respectively. According to Anderson, feminist research on divorce conducted by Abigail Steward et al. (1997) demonstrates how a feminist value-driven inquiry can produce "epistemically fruitful" outcomes by uncovering evidence that is neglected by purportedly value-free inquiry. Traditional research frames divorce as a failure of marriage and loss of opportunity to live a happy life. Accordingly, such research only looked for the negative outcomes of divorce, such as the economic hardship women experience after their divorce. In contrast, Stewart's team was open to the possibility that divorce can provide "an opportunity for personal growth" (E. Anderson, 2004, p. 14). Due to this value commitment, the researchers were able to find evidence that divorced women can develop a sense of autonomy by achieving financial independence from their husbands (Stewart et al.,

neurodiversity paradigm, the biological fact that there are variations in neurocognitive functioning within the human species leads to the normative conclusion that each form of variation should be valued and respected. In other words, it has been noted that the perceived "impairments" or "disabilities" of autistic people is due to our society's inability to accommodate the various needs of neurodiverse people.

${ }^{8} \mathrm{I}$ am indebted to an anonymous referee for pushing me to clarify this point.

${ }^{9}$ Rimland and other parents established the National Society for Autistic Children (NSAC) in 1965, a grassroots organization advocating the rights of autistic children and their families. The Board of Directors and the Professional Advisory Board of the NSAC came up with a working definition of infantile autism in the late 1970s, and it made clear that "No known factors in the psychological environment of a child have been shown to cause autism" (Ritvo \& Freeman, 1977, p. 146). 
1997, p. 102). These positive outcomes added a new understanding of divorce that was not possible by traditional research. In sum, appealing to Stewart's team's research on divorce, Anderson argues that non-epistemic value considerations can play "knowledge-enhancing roles" in scientific inquiry without harming the impartiality of science and the fair treatment of evidence (E. Anderson, 2004, p. 3).

Kourany (2010) suggests another example where non-epistemic values can positively contribute to the epistemic success of a research program. She highlights research by Carolyn West (2002a, 2002 b) on intimate partner violence. In intimate partner violence research, challenges are faced when dealing with similarities and differences across racial groups when it comes to inflicting violence on intimate partners. This is particularly noticeable when researchers want to reveal racial similarities across racial groups "without negating the experiences of Black women" subject to such violence, while, at the same time, emphasizing differences "without perpetuating the stereotype that Black Americans are inherently more violent than other ethnic groups" (West, 2002a, p. 216). Kourany focuses on how West was able to acquire relevant information from the African American women who were reluctant to cooperate due to the fear of reinforcing racial stereotypes. It was the explicit commitment to feminist egalitarian values, such as the assumption that the experiences of Black women matter and that they deserve to live free from domestic violence, which was crucial in drawing cooperation from the community (Kourany, 2010, pp. 6875).

West's research on domestic violence has a direct implication for our discussion of categorization in the social sciences. ${ }^{10}$ Committed to feminist egalitarian values, West emphasizes the need to "broaden the definition of partner violence to include psychological, emotional, and verbal abuse" (West, 2002a, p. 219). Earlier research on domestic violence only focused on physical violence and measured its severity and frequency. Not surprisingly, the phenomenon of "escalation of violence" from verbal and psychological to physical abuse was not fully appreciated (ibid., p. 220). The fact that many African American women who are victims of physical assault had prior psychological abuse, often more frequent and severe than women of other ethnic groups, would not have been revealed if researchers like West were not motivated to investigate it. Valuecommitted research of domestic violence called for expansion of its definition, and that change in definition influenced the entire process of research on domestic violence (Brigandt, 2015, p. 334). Here again, we have an example where value-laden research produces epistemically beneficial outcomes.

\section{Objections: The Value-Free Ideal?}

In the preceding section, I provided case studies from the literature against the VFI to suggest that the current discussion of values and classification can benefit from the existing values and science literature. My case study of infantile autism directly shows how value-driven inquiry led to the

\footnotetext{
${ }^{10}$ The case of domestic violence provides a good example of how researchers should make value-laden decisions before undertaking empirical research. Researchers should "specify the boundaries of entities," such as who is considered an intimate partner and what types of harm are considered to be violence, whose experiences should count (only Caucasian women?), and so forth (Ludwig, 2016, p. 1268).
} 
epistemic improvement of the category. The current understanding of infantile autism as a neurodevelopmental disorder can be attributed to Rimland's dedication to autistic children and their families. According to Griffiths and Khalidi, allowing non-epistemic purposes to shape scientific categories can be worrisome because these purposes tend to diminish the epistemic value of those categories. Contrary to that concern, the case study of infantile autism shows that serving non-epistemic purposes can have epistemically beneficial outcomes in establishing and delimiting a scientific category. In the following, I will address some potential objections to my account. In doing so, I will make it clear that Griffiths and Khalidi's concern is an endorsement of problematic assumptions of the value-free ideal of science.

\subsection{The Context Distinction Objection}

The first objection proceeds from the perception that every researcher, to some extent, brings their values, biases, and beliefs to bear on deciding what research to pursue. Values can legitimately influence the choice of research questions, but they do not and should not influence how theories are evaluated. It might be objected that the autism case only illustrates how a researcher used his value judgments in choosing a research topic and conceiving hypotheses, which is irrelevant to the stage of inquiry where evaluating hypotheses happens. In other words, the case study of autism does not show how value considerations directly affected the assessment of two competing hypotheses - the psychogenic hypothesis and the biological hypothesis. The scientific community accepted the biological hypothesis over the psychogenic one, and this choice involved purely epistemic considerations, such as which one is more empirically adequate.

This objection is based on the so-called "context distinction," which separates the process of conceiving and developing a hypothesis (i.e., the context of discovery) from the process of justifying and evaluating the hypothesis (i.e., the context of justification). It is often argued that non-epistemic value influence in the context of discovery is innocuous, while in the context of justification such an influence can corrupt parts of science. This objection, however, suggests a more fine-grained distinction between contexts of discovery and justification than Khalidi assumes. What he takes to be problematic are non-epistemic purposes that divert the purpose of discovering natural kinds. He suggests that " $[t]$ he surest way to ensure that our categories identify real kinds is to pursue a scientific method that serves epistemic purposes" (Khalidi, 2013, p. xiv). He also claims that "in order to identify [natural kinds] we must be guided by epistemic purposes and not be deflected by non-epistemic interests" (ibid., p. 213). For Khalidi, following epistemic purposes is also essential in demarcating natural kinds from folk categories: "[F]olk categories can be expected to correspond to natural kinds only when they serve an epistemic purpose" (ibid., p. 64). Here, Khalidi does not seem to care about the context distinction. His account suggests that scientific inquiry ought to be guided by epistemic purposes alone from the outset. Khalidi does not consider whether the context of discovery provides values that are then weeded out in the context of justification.

Even if we grant that the distinction between the contexts of discovery and justification matters, it is important to note that it has been substantially challenged during the last few decades. Many philosophers of science have challenged the distinction by showing that the purported epistemic independence of the context of justification from the context of discovery cannot be maintained in practice (Okruhlik, 1994; Brigandt, 2015; Bueter, 2015; Elliott \& Mckaughan, 2016). 
According to Katheleen Okruhlik (1994), non-epistemic factors influencing decisions in the context of discovery have a significant impact on theory appraisal and the content of science by limiting the pool of available theories. For example, if a sexist bias is pervasive in the current scientific community, then it tends to restrict scientists' mindset in such a way that alternative (not sexist) theories are inconceivable or prohibited. Consequently, even if the best theory is selected on purely objective grounds (in the context of justification), the selected theory can still contain sexist assumptions. Okruhlik's argument is not just about implicit bias. The general lesson we can draw from her argument is that once values enter the context of discovery, methodological rigor in the context of justification does not guarantee the elimination of values in science.

Recall that Rimland's non-epistemic value judgments in the context of discovery resulted in positive epistemic benefits in the context of justification. His value judgment that familial wellbeing matters motivated him to investigate the disorder and enabled him to find shortcomings with the psychogenic view. More importantly, his value judgments functioned as a check on the background assumptions that supplement the gap between data and hypothesis (Longino, 1990, 2002). In the psychogenic view, the data that autistic children sought excessive aloneness was interpreted as withdrawal from their uncaring mothers. Rimland's value of familial well-being enabled him to question that background assumption of the psychogenic view and explore other background assumptions. Rimland interpreted existing data differently and evaluated the received view with available experimental data. Data interpretation and theory evaluation occur at the core of scientific reasoning - the "epistemic phase" (Hicks, 2014). The case of infantile autism shows that non-epistemic value judgments can positively affect the epistemic phase of scientific inquiry - the so-called the context of justification.

\subsection{The Problem of Wishful Thinking Objection}

Another concern one might have is that the autism case would fail to dissuade scientists from following Khalidi's prescription. In particular, it might be argued that Khalidi's prescription is an effective tactic to pursue, given that scientific objectivity and integrity may be threatened by commercialization of science. Profit-driven research has been forming an ever-greater part of the scientific research, and the worry that this type of research only serves the interests of the sponsors has been growing. In biomedical research, for example, it has been noted that pharmaceutical company sponsored research tends to reach positive conclusions about new drugs (Friedberg et al., 1999). Although this "preference bias" is not the same as outright fabrication of research outcomes, it seriously degrades scientific objectivity, and thus it is epistemically harmful (Wilholt, 2009, p. 92). ${ }^{11}$ It has also been reported that researchers with financial ties measure only favorable factors and intentionally avoid measuring some risk factors that can undermine the safety of the tested drugs (Resnik, 2007). In addition, the very fact that the research proving the safety of a new drug is funded by the pharmaceutical company that developed the drug can severely damage public trust. ${ }^{12}$ These are a few examples of external influences corrupting scientific research.

\footnotetext{
${ }^{11}$ David Resnik (2000) identifies a number of types of research bias caused by financial interests. Profitdriven considerations can affect research at all stages of research, from the selection of a research topic to dissemination of research outcomes.

${ }^{12}$ Some scholars have expressed such a concern when investigating the association between researchers' positive evaluation of the safety of new drugs and their financial ties with pharmaceutical companies.
} 
Accordingly, perhaps it is better to mandate that scientists should stick to epistemic purposes and reject all non-epistemic considerations.

This objection is a familiar argument promoted by proponents of the VFI. The worry that allowing non-epistemic values to influence scientific inquiry makes researchers reach preferred conclusions has been named as the "problem of wishful thinking" (Brown, 2013, p. 835). This problem is directly relevant to the pharmaceutical cases, and it seems to provide a reason to support Khalidi's position that we should exclude non-epistemically value-laden influences all together. For example, some might criticize Rimland's research by arguing that he attempted to revise the notion of autism in such a way as to conform to or accord with his value judgments, which is an instance of the problem of wishful thinking. If the VFI is appealed to, then both the psychogenic hypothesis and the biological hypothesis, are examples of corrupted science. Work on both hypotheses violates the norm that scientists should "minimize the influence of contextual [nonepistemic] values on scientific reasoning, e.g., in gathering evidence and assessing/accepting scientific theories" (Reiss \& Sprenger, 2017, p. 21).

Anderson suggests that what advocates of the VFI are worried about is the "dogmatic character of value judgments," meaning that people who hold their values in research will be blind to disconfirming evidence and drive their research to preferred conclusions (E. Anderson, 2004, p. 3). Anderson not only argues that value judgments need not be held dogmatically, but also shows that research conducted by "nonfanatical valuer(s)" can better satisfy epistemic standards of scientific inquiry, such as fruitfulness, broad scope, and explanatory power, than other purportedly neutral research (ibid., p. 9). Returning to Anderson's example discussed earlier, what the Stewart research team did serves as a model for non-neutral but epistemically sound research. Stewart's team found cases where children exhibited high anxiety during regular visits from their noncustodial fathers after divorce. These cases were disturbing to the researchers since they were directly in conflict with the aim of revealing positive aspects of divorce. Rather than narrowmindedly holding their beliefs at the expense of the truth, the researchers decided to "continue analyzing displeasing findings in the hope of explaining them away" (ibid., p. 17). Further analysis revealed that the intense anxiety of children during the scheduled visit of their fathers was due to the anticipation of the parents' fight upon meeting, which was a typical routine prior to divorce. Based on this analysis, the Stewart team was able to make practical recommendations for the parents who divorced after much conflict, e.g., to arrange spontaneous visits (ibid., p. 17). The point of the Stewart team's research here is to demonstrate that value-committed researchers can live up to the standards of scientific inquiry, such as that any inquiry should be open to the "possibility of discovering otherwise" regardless of the inquirer's value commitments (ibid., p. 20). So, the objection that all research influenced by non-epistemic values will lead to wishful thinking is unfounded.

Their worry is exemplified in the following: "We wonder how the public would interpret the debate over calcium-channel antagonists if it knew that most of the authors participating in the debate had undisclosed financial ties with pharmaceutical manufacturers" (Stelfox et al., 1998, p. 105). 


\subsection{Ethically Neutral Classification Objection}

Those who sympathize with Khalidi can still argue that epistemically fruitful outcomes of the case studies provided in this paper do not establish the analogous result for conceptual issues. ${ }^{13}$ In other words, conceptual issues - how to delimit boundaries of concepts - can be unaffected by arguments for the indispensable roles of non-epistemic values in science in general. For example, when it comes to judging what counts as genuine instances of child abuse, researchers can and should make classificatory choices without taking a subjective stance on normative issues.

This objection is well captured in Ernest Nagel's (1961) work on the possibility of social science being "ethically neutral." Arguing against the idea that "an ethically neutral social science is inherently impossible" (ibid., p. 495), Nagel offers a way to do so regardless of the heavily normladen nature of social concepts. ${ }^{14}$ Whenever social scientists "assess" or "estimate" whether "a given characteristic is in some degree present (or absent) in a given instance," they can do their job by operationalizing social concepts (ibid., p. 492). John Dupré (2007) provides an example of how a Nagelian strategy "converts an evaluative term to a descriptive one" (p. 30). Let us assume that a social researcher investigates violent behavior in children. How can the researcher describe the degree of violence of a child? Instead of saying that "Sam is a violent little boy," the researcher can report, "Sam scored 84 on the Smith-Jones physical assertiveness scale" (Dupré, 2007, p. 29). The former statement delivers a sense of the reporter's disapproval of violence, whereas the latter statement only estimates a given case according to a given standard. By refraining from using value-laden terms, e.g., "violent," the operationalized statement specifies the object of measurement, i.e., "physical assertiveness."

The first problem with this strategy is its impracticality and inefficiency. To come up with an operationalization, a researcher has to consider a variety of theoretical accounts on violence. There can be multiple accounts of violence, not just those about physical assertiveness. Converting all possible accounts into descriptive statements is neither feasible nor efficient given limited resources. The second problem is that operationalization does not get rid of value judgments. Instead, it "eliminates values at one stage, but it only pushes them to another, less appropriate stage" (Alexandrova, 2018, p. 430) or it makes them less visible (Intemann, 2015, p. 224). In short, the conversion from evaluation to description still requires value-laden choices. Eventually, which conceptual scheme a researcher adopts turns on what actions are considered undesirable or harmful, and which scheme is considered manageable. Moreover, how to delimit the boundaries of concepts not only requires having adequate empirical data but also careful considerations of why we need that data and how to promote the aim of inquiry (Intemann, 2015, p. 224) ${ }^{15}$ The third problem is that the conversion from evaluation to description is achieved at the expense of losing "reasons for action" (Dupré, 2007, p. 30). Not only do we want to have an accurate description of violence, but we also want to do something to reduce violence. The normative consideration is not

\footnotetext{
${ }^{13}$ I thank anonymous referees for raising this worry and making suggestions.

${ }^{14}$ Anna Alexandrova (2018) explores three possible strategies a "Nagelian" can pursue. What I consider in this paper corresponds to her second formulation of a Nagelian strategy.

${ }^{15}$ Kristen Intemann (2015) provides another relevant example, the case of "biodiversity" in climate change research. Measuring impacts of climate change on biodiversity invites numerous decisions that are valueladen, such as what constitutes a significant loss to be measured.
} 
something attached to a descriptive account of violence at a later time. The normative consideration is "fundamental to negotiations about what should and should not count as" violence (ibid., p. 37). ${ }^{16}$ In the end, the elimination of "hybrid concepts" (Dupré, 2007) or "mixed claims" (Alexandrova, 2018) by converting them into purely descriptive statements is both unattainable and undesirable.

\section{Conclusion}

As we have seen, some scholars are skeptical about whether social, psychological, and psychiatric kinds can be natural kinds, because the boundaries of such kinds are partly shaped by nonepistemic considerations. Using Griffiths' terminology, both natural kinds and normative kinds go through conceptual changes but with different purposes. Normative kinds serve the aim of social reform, while natural kinds serve epistemic aims, such as inductive inference, explanation, et cetera. The worry arises when scientific categories are pressured to pursue two heterogenous aims, epistemic and normative, simultaneously. The worry is that when a category is revised due to the influence of non-epistemic values, the epistemic value of those categories will be diminished and the discovery of natural kinds will be derailed. Thus, the best strategy to uncover natural kinds, according to Khalidi, is to pursue epistemic purposes and, at the same time, exclude non-epistemic purposes.

In this paper, I have responded to this worry by providing the case study of infantile autism. The early evolution of the concept of infantile autism exhibits changes from understanding infantile autism as a form of psychosis, caused by cold parenting, to a neurodevelopmental disorder substantially involving biological factors. Establishment of the notion of infantile autism as a scientific category involved non-epistemic value judgments, e.g., that the well-being of a family with autistic children is important. The positive contributions value-driven research made in establishing and delimiting the scientific category of infantile autism included: i) how research motivated by non-epistemic value judgments led to a critical examination of the received view, thereby revealing its empirical inadequacy; ii) how value-driven research led to the expansion of the research field; and iii) how value commitments contributed to the creation and development of diagnostic criteria, helping to demarcate the category. Rather than diminishing the epistemic value of the category, non-epistemic value commitments led to the epistemic improvement of the category.

By considering potential objections, I have also tried to show that the concern over value-driven modifications of natural kinds is motivated by the VFI. Given the various arguments against the VFI, we have reasons to doubt the claim that value influence per se is harmful in scientific classification. More importantly, as shown in the case study of infantile autism, non-epistemic value judgments can be epistemically beneficial in scientific classification.

\footnotetext{
${ }^{16}$ Here, I replace "rape" from the original paper with "violence."
} 


\section{Acknowledgement}

My thanks to Marc Ereshefsky, Megan Delehanty, Ken Waters, Muhammad Ali Khalidi, Ingo Brigandt, Daniel Hicks, Stijn Conix, Celso Neto, Nima Khodabandeh and two anonymous reviewers for their valuable feedback on earlier versions of this article. I also thank audiences at the $26^{\text {th }}$ Biennial Meeting of the Philosophy of Science Association 2018 Poster Forum and the symposium "The Role of Non-Epistemic Values in Scientific Classification" at the 2019 Meeting of the International Society for the History, Philosophy and Social Studies of Biology. Financial support was provided by the Izaak Walton Killam Doctoral Scholarship at the University of Calgary.

\section{References}

Alexandrova, A. (2018). Can the Science of Well-Being Be Objective? British Journal for the Philosophy of Science, 69(2), 421-445. https://doi.org/10.1093/bjps/axw027

Anderson, E. (2004). Uses of Value Judgments in Science: A General Argument, with Lessons from a Case Study of Feminist Research on Divorce. Hypatia: A Journal of Feminist Philosophy, 19(1), 1-24. https://doi.org/10.1111/j.1527-2001.2004.tb01266.x

Anderson, R. E., Edwards, L., Silver, K. E., \& Johnson, D. M. (2018). Intergenerational transmission of child abuse: Predictors of child abuse potential among racially diverse women residing in domestic violence shelters. Child Abuse \& Neglect, 85(August 2018), 80-90. https://doi.org/10.1016/j.chiabu.2018.08.004

Badesch, S. (2011). Where We've Been and Where We're Going: The Autism Society's Proud History. Autism Advocate, 7-11.

Baker, J. P. (2010). Autism in 1959: Joey the mechanical boy. Pediatrics, 125(6), 1101-1103. https://doi.org/10.1542/peds.2010-0846

Bettelheim, B. (1967). The Empty Fortress: Infantile Autism and the Birth of the Self. The Free Press.

Boullin, D. J., Coleman, M., O’Brien, R. A., \& Rimland, B. (1971). Laboratory predictions of infantile autism based on 5-hydroxytryptamine efflux from blood platelets and their correlation with the rimland E-2 score. Journal of Autism and Childhood Schizophrenia, 1(1), 63-71. https://doi.org/10.1007/BF01537743

Brigandt, I. (2015). Social values influence the adequacy conditions of scientific theories: beyond inductive risk. Canadian Journal of Philosophy, 45(3), 326-356. https://doi.org/10.1080/00455091.2015.1079004

Brown, M. J. (2013). Values in Science beyond Underdetermination and Inductive Risk. Philosophy of Science, 80(5), 829-839. https://doi.org/10.1086/673720

Bueter, A. (2015). The irreducibility of value-freedom to theory assessment. Studies in History and Philosophy of Science, 49, 18-26. https://doi.org/10.1016/j.shpsa.2014.10.006

Carey, B. (2006). Obituaries: Bernard Rimland, 78, Scientist Who Revised the View of Autism, Dies. The New York Times, A21. https://www.nytimes.com/2006/11/28/obituaries/28rimland.html

Casanova, E. L., \& Casanova, M. F. (2019). Defining Autism: A Guide to Brain, Biology, and Behavior. Jessica Kingsley Publishers.

Chaste, P., \& Leboyer, M. (2012). Autism risk factors: Genes, environment, and gene-environment 
interactions. Dialogues in Clinical Neuroscience, 14(3), 281-292. https://doi.org/1958-5969

Crowell, J. A., Keluskar, J., \& Gorecki, A. (2019). Parenting behavior and the development of children with autism spectrum disorder. Comprehensive Psychiatry, 90, 21-29.

https://doi.org/10.1016/j.comppsych.2018.11.007

Douglas, V., \& Sanders, F. A. (1968). A Pilot Study of Rimland'S Diagnostic Check List With Autistic and Mentally Retarded Children. Journal of Child Psychology and Psychiatry, 9(2), 105-109. https://doi.org/10.1111/j.1469-7610.1968.tb02214.x

Dupré, J. (2007). Fact and Value. In H. Kincaid, J. Dupré, \& A. Wylie (Eds.), Value-Free Science?: Ideals and Illusions (pp. 27-41). Oxford University Press.

Edelson, S. M. (2014). “Infantile Autism”: 50 Years Later. http://www.autism.com/50thanniversaryinfantileautism

Eisenberg, L., \& Kanner, L. (1956). Early Infantile Autism, 1943-1955. The American Journal of Orthopsychiatry, 26, 556-566. https://doi.org/10.4159/harvard.9780674367012.c2

Elliott, K. C., \& Mckaughan, D. J. (2016). How Values in Scientific Discovery and Pursuit Alter Theory Appraisal. Philosophy of Science, 76(5), 598-611. https://doi.org/10.1086/605807

Eveloff, H. H. (1960). Autistic Child. Archives of General Psychiatry, 3(1), 66-81.

Friedberg, M., Saffran, B., Stinson, T. J., Nelson, W., \& Bennett, C. L. (1999). Evaluation of Conflict of Interest in Economic Analyses of New Drugs Used in Oncology. JAMA, 282(15), 1453-1457. https://doi.org/10.1001/jama.282.15.1453

Griffiths, P. E. (1997). What emotions really are: the problem of psychological categories. University of Chicago Press.

Griffiths, P. E. (2003). Is Emotion a Natural Kind? In Thinking about Emotion: Contemporary Philosophers on Emotion (pp. 233-249). Oxford University Press.

Griffiths, P. E. (2004). Emotions as Natural and Normative Kinds. Philosophy of Science, 71(5), 901911. https://doi.org/10.1086/425944

Grove, L. (1984). A World Unto Himself. The Washington Post. https://www.washingtonpost.com/archive/lifestyle/1984/08/05/a-world-unto-himself/61aa6874$806 \mathrm{a}-4 \mathrm{cb} 5-9222-\mathrm{fb} 779 \mathrm{cddd} 4 \mathrm{fc} /$

Hacking, I. (1988). The Sociology of Knowledge About Child Abuse. Nô̂s, 22(1), 53-63. https://doi.org/10.2307/2215550

Hacking, I. (1991). The making and molding of child abuse. Critical Inquiry, 17(2), 253-288. https://doi.org/10.1086/448583

Hacking, I. (1999). The Social Construction of What? Harvard University Press.

Hicks, D. (2014). A new direction for science and values. Synthese, 191(14), 3271-3295. https://doi.org/10.1007/s11229-014-0447-9

Intemann, K. (2015). Distinguishing between legitimate and illegitimate values in climate modeling. European Journal for Philosophy of Science, 5(2), 217-232.

Jaarsma, P., \& Welin, S. (2012). Autism as a natural human variation: Reflections on the claims of the neurodiversity movement. Health Care Analysis, 20(1), 20-30. https://doi.org/10.1007/s10728011-0169-9

Kanner, L. (1943). Autistic disturbances of affective contact. Nervous Child, 2, 217-250.

Kanner, L. (1949). Problems of nosology and psychodynamics of early infantile autism. The Americal Journal of Orthopsychiatry, 19, 416-426.

Kanner, L. (1960). Medicine: The Child Is Father. Time. 
http://content.time.com/time/magazine/article/0,9171,826528,00.html

Khalidi, M. A. (2013). Natural Categories and Human Kinds: Classification in the Natural World. Cambridge University Press.

Kourany, J. A. (2010). Philosophy of Science after Feminism. Oxford University Press.

Lai, M.-C., Lombardo, M. V, \& Baron-Cohen, S. (2014). Autism. The Lancet, 383(9920), 896-910. https://doi.org/10.1016/S0140-6736(13)61539-1

Longino, H. (1990). Science as Social knowledge: Values and Objectivity in Scientific Inquiry. Princeton University Press.

Longino, H. (2002). The Fate of Knowledge. Princeton University Press.

Lord, C., \& Corsello, C. (2005). Diagnostic Instruments in Autistic Spectrum Disorders. In F. R. Volkmar, R. Paul, A. Klin, \& D. J. Cohen (Eds.), Handbook of Autism and Pervasive Developmental Disorders (pp. 730-771). John Wiley \& Sons, Incorporated. https://doi.org/10.1002/9780470939352.ch2

Ludwig, D. (2016). Ontological Choices and the Value-Free Ideal. Erkenntnis, 81(6), 1253-1272. https://doi.org/10.1007/s10670-015-9793-3

Maugh II, T. H. (2006). Obituaries: Bernard Rimland, 78; author was the father of modern autism research. Los Angeles Times. http://articles.latimes.com/2006/nov/26/local/me-rimland26

Nagel, E. (1961). Methodological Problems of the Social Sciences. In The Structure of Science: Problems in the Logic of Scientific Explanation (pp. 447-502). Harcourt, Brace \& World Inc.

Okruhlik, K. (1994). Gender and the biological sciences. Canadian Journal of Philosophy (Supplementary Volume), 20, 21-42. https://doi.org/10.1080/00455091.1994.10717393

Press, A. (2006). Autism pioneer Rimland dead at 78. Los Angeles Daily News. https://www.dailynews.com/2006/11/27/autism-pioneer-rimland-dead-at-78/

Reiss, J., \& Sprenger, J. (2017). Scientific Objectivity. In E. N. Zalta (Ed.), The Stanford Encyclopedia of Philosophy (Winter 2017 Edition) (pp. 1-74). https://plato.stanford.edu/archives/win2017/entries/scientific-objectivity/

Resnik, D. B. (2000). Financial Interests and Research Bias. Perspectives on Science, 8(3), 255-285. https://doi.org/10.1162/106361400750340497

Resnik, D. B. (2007). The price of truth: How money affects the norms of science. Oxford University Press. https://doi.org/10.1017/S0266267108001739

Rimland, B. (1964). Infantile Autism: The Syndrome and Its Implications for a Neural Theory of Behavior. Meredith Publishing Company.

Rimland, B. (1971). The differentiation of childhood psychoses: An analysis of checklists for 2,218 psychotic children. Journal of Autism and Childhood Schizophrenia, 1(2), 161-174. https://doi.org/10.1007/BF01537955

Rimland, B. (1984). Diagnostic checklist form E2: A reply to Parks. Journal of Autism and Developmental Disorders, 14(3), 343-346. https://doi.org/10.1007/BF02409584

Rimland, B. (1993). Plain Talk about PDD and the Diagnosis of Autism. Autism Research Review International, $7(2)$.

Rimland, B. (1994). The second great autism watershed. Autism Research Review International, 8(1), 3. http://www.ariconference.com/ari/newsletter/081/page3.pdf

Shattock, P. (2006). Bernard Rimland: Parent and practitioner revolutionising the treatment of autism. The Guardian. https://www.theguardian.com/news/2006/dec/06/guardianobituaries.mainsection Silberman, S. (2015). NeuroTribes: The Legacy of Autism and the Future of Neurodiversity. Penguin. 
Stelfox, H. T., Chua, G., O'rourke, K., \& Detsky, A. S. (1998). Conflict of interest in the debate over calcium-channel antagonists. The New England Journal of Medicine, 338(2), 101-106. https://doi.org/10.1056/NEJM199806043382313

Stewart, A. J., Copeland, A. P., Lane, C. N., Malley, J. E., \& Barenbaum, N. B. (1997). Separating together: how divorce transforms families. Guilford Press.

West, C. (2002a). Black Battered Women: New Directions for Research and Black Feminist Theory. In L. H. Collins, M. R. Dunlap, \& J. C. Chrisler (Eds.), Charting a New Course for Feminist Psychology (pp. 216-237). Praeger.

West, C. (2002b). Violence in the Lives of Black Women: Battered, Black, and Blue. The Haworth Press.

Wilholt, T. (2009). Bias and values in scientific research. Studies in History and Philosophy of Science, 40(1), 92-101. https://doi.org/10.1016/j.shpsa.2008.12.005

Zeldovich, L. (2018). The evolution of 'autism' as a diagnosis, explained. Spectrum, Autism Research News. https://www.spectrumnews.org/news/evolution-autism-diagnosis-explained/ 